\title{
REGÊNCIA E IMPRENSA: PERCURSOS HISTORIOGRÁFICOS
}

\author{
Marcello Otávio Neri de Campos Basile ${ }^{1 ; 2}$
}

\section{Resumo}

O artigo realiza uma síntese da produção historiográfica acerca do período regencial (1831-1840), abordando os principais eixos temáticos que a configuram, com ênfase nas obras que têm a imprensa como objeto de estudo.

\section{Palavras-chave}

Regência - imprensa - historiografia.

\section{Abstract}

The paper presents a synthesis of the historical researches about the Regency period (1831-1840). It focuses on the main topics of study, with emphasis on the works that approach the press as an object of analysis.

\section{Keywords}

Regency - press - historiography.

Não faz muito tempo, o período regencial (1831-1840) ainda era predominantemente visto sob uma ótica negativa ou relegado a lugar secundário nas pesquisas históricas. A lenda negra da Regência remonta aos seus próprios contemporâneos, desiludidos ou insatisfeitos com o rumo tomado pelos acontecimentos após a abdicação de Pedro I, e ganhou força na produção de letrados e políticos conservadores do Segundo Reinado. Homens como Justiniano José da Rocha, visconde do Uruguai, Pereira da Silva, Moreira de Azevedo e Joaquim Nabuco caracterizaram a década de 1830 como época anárquica e anômala, marcada por intensos conflitos políticos, por radicalismos à esquerda e à direita, e por dezenas de revoltas populares disseminadas por todo o país, que teriam constituído ameaças à formação e à preservação da nação brasileira, em contraste com a imagem de estabilidade, ordem e prosperidade cunhada para o Segundo Reinado ${ }^{3}$. Visão mais positiva encontra-se, por outro lado, nas obras de liberais como Torres Homem, Theophilo Ottoni, Cristiano Ottoni e Tavares Bastos, que enalteceram a fase inicial das regências trinas (1831-1835) como o triunfo das liberdades, descentralizando o poder e mitigando os resíduos absolutistas em voga no Primeiro Reinado. Mas tal movimento, ponderam esses autores, teria sido logo freado e eclipsado pela guinada centralizadora operada pelo Regresso conservador, a partir de $1837^{4}$.

Matizada e refinada pela perspectiva de interpretação da Abdicação como nacionalização da Independência e de subsequente avanço inicial do espírito liberal, a visão anômica acerca do tempo das regências imprimiu, contudo, fortes e duradouras marcas sobre a historiografia ao longo de grande parte do século XX. O instigante panfleto de Justiniano José da Rocha consagrou-se como principal matriz interpretativa do período, acompanhado pela grande obra de Joaquim Nabuco. Já nas primeiras décadas, essa visão ganhou inconfundível expressão nas obras de Aurelino Leal e de Alfredo Valladão, bem como, em geral, nos 70 trabalhos apresentados

\footnotetext{
${ }^{1}$ Universidade Federal Rural do Rio de Janeiro. Rio de Janeiro - Brasil.

2 Doutor em História (PPGHIS - UFRJ, 2004) e Professor associado de História do Brasil do Departamento de História da Universidade Federal Rural do Rio de Janeiro - Instituto Multidisciplinar.

${ }^{3}$ ROCHA, Justiniano José da. Acção; reacção; transacção. Duas palavras acerca da actualidade politica do Brazil. Rio de Janeiro, Typ. Imp. e Const. de J. Villeneuve e Comp., 1855, pp. 15-37; URUGUAI, Visconde do. Ensaio sobre o direito administrativo. In: Idem. Visconde do Uruguai. Organização, introdução e notas de José Murilo de Carvalho. São Paulo: Editora 34, 2002, especialmente pp. 449-467 (1 ${ }^{a}$ ed. - 1862); SILVA, João Manuel Pereira da. Memórias do meu tempo. 2a ed. Brasília: Senado Federal, 2003, capítulo I; AZEVEDO, Moreira de. Historia patria: o Brazil de 1831 a 1840. Rio de Janeiro: B. L. Garnier, 1884; e NABUCO, Joaquim. Um estadista do Império. 2 vs. $5^{\text {a }}$ ed. Rio de Janeiro: Topbooks, 1997, v. 1, pp. 52-59 e 65-67 (1ª ed., em 3 vs., 1897-1899).

${ }^{4}$ TIMANDRO (Francisco de Salles Torres Homem). O libelo do povo. In: MAGALHÃES JÚNIOR, Raimundo (org.). Três panfletários do Segundo Reinado. São Paulo: Nacional, 1956, pp. 75-92 (1ª ed. - 1849); OTTONI, Theophilo Benedicto. Circular Dedicada aos Srs. Eleitores de Senadores pela Provincia de Minas-Geraes. In: Revista do Instituto Historico e Geographico Brasileiro (doravante, RIHGB), t. LXXVIII - parte II. 2a ed. Rio de Janeiro: Imprensa Nacional, 1916, pp. 205-256 (1 ${ }^{\text {a }}$ ed. - 1860); OTONI, Cristiano

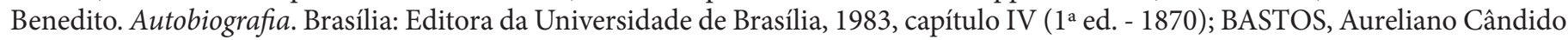
Tavares. A província: estudo sobre a descentralização no Brasil. 3a ed. São Paulo: Nacional / Brasília: Instituto Nacional do Livro, 1975, principalmente capítulo I da parte segunda ( $1^{\text {a }}$ ed. - 1870).
} 
no Segundo Congresso de História Nacional, promovido em 1931 pelo Instituto Histórico e Geográfico Brasileiro. ${ }^{5}$ Lucia Guimarães chamou atenção, a propósito, para o fato de que a sugestão, feita por Max Fleiüs em 1926, de realização de um congresso dedicado à efeméride dos 100 anos da Revolução do 7 de Abril não foi bem acolhida pelos membros da comissão do IHGB encarregada de apreciá-la, encabeçada por Pandiá Calógeras. "A Abdicação parecia-lhes um acontecimento secundário, que não estava à altura dos grandes fastos nacionais"'. Restou, então, à Alfredo Valladão a responsabilidade de arcar sozinho com a organização do evento, cuja matéria fora desde o início concebida como uma espécie de desdobramento do processo de emancipação política do Brasil, amplamente celebrado pelo próprio IHGB em 1914, no Primeiro Congresso de História Nacional.

Essa perspectiva de análise, que atrelava a Regência à Independência, e reprovava os excessos de radicalismo que ameaçariam a ordem, o governo e as instituições monárquicas, encontrou sua melhor expressão no notável conjunto de biografias dos fundadores do Império produzidas por Octavio Tarquinio de Souza, entre as décadas de 1930 e $1950^{7}$. Trata-se, ainda hoje, de uma das mais importantes obras sobre a época em questão, o que assevera a pouca atenção dispensada à Regência pelos historiadores nas décadas seguintes. Tanto assim que outra referência clássica e imprescindível, o artigo de Paulo Pereira de Castro, publicado nos anos de 1970, apresenta como principais contribuições a revisitação ao período e uma síntese mais equilibrada do contexto das disputas políticas regenciais; mas pouco avança em termos de inovações de pesquisa ${ }^{8}$.

Ao contrário do que estranhamente pensava o brasilianista Rollie Poppino nessa mesma época ${ }^{9}$, as regências eram um dos períodos menos estudados e ainda menos compreendidos da história do Brasil, oferecendo ampla gama de objetos e questões abertos à pesquisa histórica. Até então, apenas dois temas específicos haviam merecido certa atenção dos historiadores: a imprensa periódica e as revoltas provinciais. No primeiro caso, os trabalhos existentes abordaram os jornais regenciais no rol de estudos mais amplos sobre o desenvolvimento da imprensa brasileira ao longo de conjunturas históricas diversas, restringindo-se, quase sempre, a levantamentos das publicações (periódicas) e a breves considerações descritivas sobre elas ${ }^{10}$. No segundo caso, os trabalhos sobre as revoltas regenciais foram geralmente produzidos como estudos de caso circunscritos ao movimento em questão, limitando-se aos de maior vulto e a análises factuais dos acontecimentos, tratados como efemérides (seja na linha condenatória da anarquia; seja, positivamente, visando construir memórias históricas regionais) ${ }^{11}$. Não obstante a importância que tiveram em suas épocas, tais obras carecem de maior

\footnotetext{
${ }^{5}$ LEAL, Aurelino. Do Acto Addicional à Maioridade (Historia constitucional e politica). Rio de Janeiro: [Imprensa Naval], 1915; VALLADÃO, Alfredo. Da Aclamação à Maioridade (1822-1840) e outros trabalhos históricos. Rio de Janeiro: Freitas Bastos, $3^{\mathrm{a}}$ ed. , 1973 [ $1^{\text {a }}$ ed. - 1937]; e Anais do Segundo Congresso de História Nacional. In: RIHGB. Rio de Janeiro: Imprensa Nacional, 5 vs ,1941-1946. ${ }^{6}$ GUIMARÃES, Lucia Maria Paschoal. Da Escola Palatina ao Silogeu: Instituto Histórico e Geográfico Brasileiro (1889-1938). Rio de Janeiro: Museu da República, 2007, p. 144.
}

${ }^{7}$ SOUZA, Octavio Tarquinio de. História dos fundadores do Império do Brasil. 10 vs. Rio de Janeiro: José Olympio, 1957.

${ }^{8}$ CASTRO, Paulo Pereira de. A 'experiência republicana', 1831-1840. In: HOLANDA, Sérgio Buarque de (dir.), e CAMPOS, Pedro Moacyr (assist.). História geral da civilização brasileira, t. II - o Brasil monárquico, $2^{\circ} v$. - dispersão e unidade. $5^{\mathrm{a}}$ ed. São Paulo: Difel, 1985.

${ }^{9}$ POPPINO, Rollie E. A Regência e a história do Brasil: um desafio aos historiadores. In: RIHGB, v. 307. Rio de Janeiro: Departamento de Imprensa Nacional, 1976, p. 146. O autor, curiosamente, chega a afirmar que "seria difícil aperfeiçoar muito nossos conhecimentos de vários aspectos da história do período regencial", a exemplo da imprensa da Corte, da maçonaria, das revoltas provinciais e da atuação dos grandes personagens da política nacional (p. 147).

${ }^{10}$ Cf. AZEVEDO, Moreira de. Origem e desenvolvimento da imprensa no Rio de Janeiro. In RIHGB, t. XXVIII - parte segunda. Rio de Janeiro: B. L. Garnier, 1865; CARVALHO, Alfredo de. A imprensa baiana de 1811-1898. In: Revista do Instituto Geographico e Historico da Bahia, v. 6 - nos 21-22. Bahia, 1899; IDEM. Jornaes pernambucanos de 1821-1898. Recife: Typographia do Jornal do Recife, 1899; IDEM. Annaes da imprensa periodica pernambucana de 1821 a 1908. Recife: Typographia do Jornal do Recife, 1908; IDEM. Genese e progressos da imprensa periodica no Brazil. In: RIHGB, tomo consagrado à Exposição Commemorativa do Primeiro Centenario da Imprensa Periodica no Brazil - parte 1. Rio de Janeiro: Imprensa Nacional, 1908; FONSECA, Gondin da. Biografia do jornalismo carioca (1808-1908). Rio de Janeiro: Quaresma, 1941; VIANNA, Helio. Contribuição à história da imprensa brasileira (1812-1869). Rio de Janeiro: Imprensa Nacional / Ministério da Educação e Saúde - Instituto Nacional do Livro, 1945; NASCIMENTO, Luiz do. História da imprensa de Pernambuco (1821-1954). 14 vs. Recife: Universidade Federal de Pernambuco Imprensa Universitária, 1967-1982; SODRÉ, Nelson Werneck. A história da imprensa no Brasil. Rio de Janeiro: Civilização Brasileira, 1966; IPANEMA, Marcello; IPANEMA, Cybelle. Imprensa na Regência: observações estatísticas e de opinião pública. In: RIHGB, v. 307. Rio de Janeiro: Departamento de Imprensa Nacional, 1976; IDEM. Imprensa fluminense: ensaios e trajetos. Rio de Janeiro: Instituto de Comunicação Ipanema, 1984.

${ }^{11}$ Vide a série de artigos publicados na RIHGB de MAGALHÃES, Domingos José Gonçalves de. Memoria historica e documentada da revolução da provincia do Maranhão desde 1839 até 1840: (t. X, 1848); e de AZEVEDO, Manuel Duarte Moreira de. Sedição militar na Ilha das Cobras em 1831 (t. XXXIV - parte 2, 1871), Os tiros no theatro: motim popular no Rio de Janeiro (t. XXXVI parte 2, 1873), Sedição militar de julho de 1831 no Rio de Janeiro (t. XXXVII - parte 2, 1874), Motim politico de 3 de abril de 1832 no Rio de Janeiro (t. XXXVII - parte 2, 1874); Motim politico de dezembro de 1833 no Rio de Janeiro: remoção do tutor do imperador (t. XXXIX - parte 2, 1876). Ver também RAIOL, Domingos Antônio. Motins politicos, ou história dos principais acontecimentos politicos 
densidade analítica, rigor metodológico e conceitual, e visão relacional de conjunto.

A partir do final da década de 1970, com o desenvolvimento dos cursos de pós-graduação no país e a consequente busca por temas inovadores, enfoques originais e fontes pouco exploradas, novas pesquisas revigoraram os estudos sobre as regências. Por um lado, possibilitaram sínteses mais elaboradas sobre o período, sintonizadas com esses avanços ${ }^{12}$. Por outro, conformaram alguns eixos temáticos, cujos objetos frequentemente entrecruzam-se. Destaco seis eixos.

A dinâmica da formação do Estado nacional e o desenho institucional pautados nas relações entre Corte e províncias, entre governo imperial e elites regionais, e nos embates entre centralização descentralização têm sido um dos focos recentes de análise ${ }^{13}$. Outro campo profícuo, fomentado pelas agudas divisões intestinas entre as elites regenciais e pela ampla pluralidade de ideias, refere-se às investigações acerca da atuação e dos projetos empreendidos por grupos e atores políticos. ${ }^{14}$ Assunto ainda pouco explorado, a despeito do levantamento pioneiro feito por Moreira de Azevedo, é o rico movimento associativo, largamente desenvolvido durante as regências, abarcando dezenas de associações de naturezas diversas ${ }^{15}$. Objeto que começa a merecer atenção é o da festividades cívicas, que, especialmente no período em questão, cumpriram importante papel na mobilização das mais diversas camadas sociais e na afirmação dos valores nacionais ${ }^{16}$. Por sua vez, o tema clássico

da província do Pará desde o ano de 1821 até 1835.3 vs. $2^{\text {a }}$ ed. [Belém]: Universidade Federal do Pará, 1970 [1ª ed. - 1865]; BRASIL, Joaquim Francisco de Assis. História da república rio-grandense. Porto Alegre: Cia. União de Seguros Gerais, 1982 [1 ${ }^{\text {a }}$ ed. - 1882]; IDEM. A Guerra dos Farrapos. Rio de Janeiro: Adersen, 1934; VARELA, Alfredo. Revoluções cisplatinas: a república rio-grandense. 2 vs. Porto: Chardron, 1915; AMARAL, José Ribeiro do. Apontamentos para a historia da revolução da Balaiada na provincia do Maranhão. 3 vs. Maranhão: Typ. Teixeira, 1898 / 1900 / 1906; HURLEY, Henrique Jorge. A Cabanagem. Belém: Livraria Clássica, 1936; AMARAL, Braz do. A Sabinada. In: PAEBa, v. II. Salvador, 1938; VIANNA FILHO, Luiz. A Sabinada (a República bahiana de 1837). Rio de Janeiro: José Olympio, 1938; SERRA, Astolfo. A Balaiada. Rio de Janeiro: Biblioteca do Exército, 1946.

${ }^{12}$ Ver FAZOLI FILHO, Arnaldo. O período regencial. 2a ed. São Paulo: Ática, 1994; LYRA, Maria de Lourdes Viana. O Império em construção: Primeiro Reinado e Regências. São Paulo: Atual, 2000; MOREL, Marco. O período das Regências (1831-1840). Rio de Janeiro: Jorge Zahar, 2003; BASILE, Marcello. O laboratório da nação: a era regencial (1831-1840). In: GRINBERG, Keila, e SALLES, Ricardo (org.). O Brasil imperial, v. II: 1831-1870. Rio de Janeiro: Civilização Brasileira, 2009; e IDEM. The "print arena": press, politics, and the public sphere in the Brazilian Empire, 1820s-1840s. In: CASTILHO, Celso, CRIBELLI, Teresa, e KRAAY, Hendrik (org.). Press, power, and culture in Imperial Brazil, 1822-1889. Albuquerque: University of New Mexico Press (no prelo).

${ }^{13}$ GOUVÊA, Maria de Fátima Silva. O Império das províncias: Rio de Janeiro, 1822-1889. Rio de Janeiro: Civilização Brasileira, 2008; DOLHNIKOFF, Miriam. O pacto imperial: origens do federalismo no Brasil do século XIX. São Paulo: Globo, 2005; SLEMIAN, Andréa. Sob o império das leis: constituição e unidade nacional na formação do Brasil (1822-1834). São Paulo: Aderaldo \& Rothschild / Fapesp, 2009; ANDRADE, Marcos Ferreira de. Elites regionais e a formação do Estado imperial brasileiro: Minas Gerais - Campanha da Princesa (1799-1850). Rio de Janeiro: Arquivo Nacional, 2008; e PEREIRA, Christiane Peres. O pacto constitucional: a dinâmica política entre Corte e províncias no Império do Brasil (1823-1834). Tese de Doutorado. Seropédica: PPHR - UFRRJ, 2018.

${ }^{14}$ LENHARO, Alcir. As tropas da moderação: o abastecimento da Corte na formação política do Brasil, 1808-1842. São Paulo: Símbolo, 1979; MOREL, Marco. Cipriano Barata na Sentinela da Liberdade. Salvador: Academia de Letras da Bahia / Assembléia Legislativa do Estado da Bahia, 2001; IDEM. As transformações dos espaços públicos: imprensa, atores políticos e sociabilidades na Cidade Imperial (1820-1840). São Paulo: Hucitec, 2005; BASILE, Marcello Otávio. Ezequiel Corrêa dos Santos: um jacobino na Corte imperial. Rio de Janeiro: Editora FGV, 2001; IDEM. Anarquistas, rusguentos e demagogos: os liberais exaltados e a formação da esfera pública na Corte imperial (1829-1834). Dissertação de Mestrado. Rio de Janeiro: PPGHIS - UFRJ, 2000; IDEM. O Império em construção: projetos de Brasil e ação politica na Corte regencial. Tese de Doutorado. Rio de Janeiro: PPGHIS - UFRJ, 2004; NEEDELL, Jeffrey D. Party formation and State-making: the Conservative Party and the reconstruction of the brazilian State, 1831-1840. In: Hispanic American Historical Review, v. 81 - n 2. Duke University Press, maio de 2001; IDEM. The Party of Order: the conservatives, the State, and slavery in the Brazilian Monarchy, 1831-1871. Stanford: Stanford University Press, 2006; SILVA, Wlamir. Liberais e povo: a construção da hegemonia liberal-moderada na província de Minas Gerais (1830-1834). São Paulo: Hucitec / Belo Horizonte: Fapemig, 2009; e ARAUUJO, Reginaldo Alves de. A parte no partido: relações de poder e política na formação do Estado nacional brasileiro, na província do Ceará (1821-1841). Tese de Doutorado. Fortaleza: PPGH - UFC, 2018.

${ }^{15}$ WERNET, Augustin. As sociedades políticas da província de São Paulo na primeira metade do período regencial. Tese de Doutorado. 2 vs. São Paulo: FFLCH - Usp, 1975; IDEM. Sociedades políticas (1831-1832). São Paulo: Cultrix / Brasília: Instituto Nacional do Livro, 1978; ANDRADE, Manuel Correia de. Movimentos nativistas em Pernambuco: Setembrizada e Novembrada. Recife: Universidade Federal de Pernambuco, 1974, capítulo V; RANGEL, Genaro. Semeadura e colheita: memória histórica da Imperial Sociedade Amante da Instrução. Belo Horizonte: O Lutador, 1979, capítulos I a VII; SILVA, José Luiz Werneck da. A Sociedade Auxiliadora da Indústria Nacional (1827-1904) na formação social brasileira: a conjuntura de 1871 a 1877. Dissertação de Mestrado. 2 vs. Niterói: ICHF - UFF, 1979, capítulos II do v. I e III do v. II; GUIMARÃES, Lucia Maria Paschoal. Em nome da ordem e da moderação: a trajetória da Sociedade Defensora da Liberdade e da Independência Nacional do Rio de Janeiro. Dissertação de Mestrado. Rio de Janeiro: PPGHIS - UFRJ, 1990; MOREL, Marco. As transformações..., ob. cit., parte III; BASILE, Marcello Otávio. Ezequiel..., ob. cit., último capítulo; IDEM. O Império..., ob. cit., capítulos III, VIII e XII; e FONSECA, Silvia Carla Pereira de Brito. A ideia de República no Império do Brasil: Rio de Janeiro e Pernambuco (1824-1834). Jundiaí: Paco, 2016, capítulo 6. O artigo pioneiro citado é o de AZEVEDO, Manuel Duarte Moreira de. Sociedades fundadas no Brazil desde os tempos coloniaes até o começo do actual Reinado. In: Revista trimensal do Instituto Historico Geographico Brazileiro, t. XLVIII - parte 2. Rio de Janeiro: Typographia de Laemmert, 1885.

${ }^{16}$ KRAAY, Hendrik. Days of national festivity in Rio de Janeiro, Brazil, 1823-1889. Stanford: Stanford University Press, 2013; Idem. Between Brazil and Bahia: celebrating Dois de Julho in nineteenth-century Salvador. In: Journal of Latin American Studies, $\mathrm{n}^{\circ} 31$. Cambridge: Cambridge University Press, 1999; Idem. Definindo nação e Estado: rituais cívicos na Bahia pós-Independência (1823- 
das revoltas regenciais tem sido revisitado sob novas perspectivas por diversos historiadores, abordando maior variedade de movimentos e iluminando questões antes pouco problematizadas, como participação popular, cultura política, modelos de ação e esfera pública ${ }^{17}$.

Mas o campo de pesquisa que tem conhecido maiores avanços é o da imprensa regencial, tanto como fonte, quanto como objeto de análise, em consonância com o mesmo uso privilegiado feito para outros contextos históricos oitocentistas. Observa-se nesses trabalhos a superação das interpretações que tradicionalmente concebiam a imprensa como reveladora da verdade dos fatos, como instrumento ideológico dos interesses de grupos dominantes ou ainda como espécie de quarto poder que determinava o rumo dos acontecimentos. Desenvolvem-se novas perspectivas de análise, como identidades e projetos políticos; linguagens e conceitos políticos; técnicas discursivas e estratégias de argumentação retórica; opinião pública e espaços de sociabilidade; biografias e trajetórias de redatores, tipógrafos e livreiros. E tanto as publicações da Corte, quanto as das 15 províncias $^{18}$ onde a imprensa periódica já se fazia então presente têm sido objeto de investigação ${ }^{19}$.

Durante as regências, particularmente entre 1831 e 1833, as publicações periódicas alcançaram o mais alto nível quantitativo observado em toda a primeira metade do século ${ }^{20}$. Explicam o fenômeno a vacância do trono,

1850). In: Topoi: revista de História, $\mathrm{n}^{\circ}$ 3. Rio de Janeiro: 7 Letras, setembro de 2001; CHAMON, Carla Simone. Festejos imperiais: festas cívicas em Minas Gerais (1815-1845). Bragança Paulista: Edusf, 2002; e BASILE, Marcello. Festas cívicas na Corte regencial. In: Varia Historia, v. 22 - n 36. Belo Horizonte: Programa de Pós-Graduação em História da UFMG, julho-dezembro de 2006.

${ }^{17}$ Por exemplo, DI PAOLO, Pasquale. Cabanagem: a revolução popular da Amazônia. Belém: Conselho Estadual de Cultura, 1985; SALLES, Vicente. Memorial da cabanagem: esboço do pensamento político-revolucionário no Grão-Pará. Belém: Cejup, 1992; PINHEIRO, Luís Balkar Sá Peixoto. Visões da Cabanagem: uma revolta popular e suas representações na historiografia. Manaus: Valer, 2001; SANTOS, Maria Januária Vilela. A Balaiada e a insurreição de escravos no Maranhão. São Paulo: Ática, 1983; JANOTI, Maria de Lourdes Mônaco. A Balaiada. São Paulo: Brasiliense, 1987; DIAS, Claudete Maria Miranda, Balaios e bem-te-vis: a guerrilha sertaneja. Teresina: Fundação Cultural Monsenhor Chaves, 1995; LEITMAN, Spencer. Raízes sócio-econômicas da Guerra dos Farrapos: um capítulo da história do Brasil no século XIX. Rio de Janeiro: Graal, 1979; PESAVENTO, Sandra Jatahy et alii. A revolução Farroupilha: história e interpretação. Porto Alegre: Mercado Aberto, 1985; RIBEIRO, José Iran. O Império e as revoltas: estado e nação nas trajetórias dos militares do Exército imperial no contexto da Guerra dos Farrapos. Rio de Janeiro: Arquivo Nacional, 2013; SOUZA, Paulo César. A Sabinada: a revolta separatista da Bahia, 1837. São Paulo: Círculo do Livro, 1987; LOPES, Juliana Serzedello Crespim. Identidades políticas e raciais na Sabinada (Bahia, 1837-1838). São Paulo: Alameda, 2013; ANDRADE, Manuel Correia de. Movimentos nativistas em Pernambuco: Setembrizada e Novembrada. Recife: Universidade Federal de Pernambuco, 1974; FREITAS, Décio. Os guerrilheiros do imperador. Rio de Janeiro: Graal, 1978; LINDOSO, Dirceu. A utopia armada: rebeliões de pobres nas matas do Tombo Real (1832-1850). Rio de Janeiro: Paz e Terra, 1983; CARVALHO, Marcus Joaquim Maciel de. Hegemony and rebellion in Pernambuco (Brazil), 1821-1835. Tese de Doutorado. Urbana: University of Illinois at Urbana-Champaign, 1989; RIBEIRO, Gladys Sabina. A liberdade em construção: identidade nacional e conflitos antilusitanos no Primeiro Reinado. Rio de Janeiro: Relume Dumará / Faperj, 2002; BASILE, Marcello. O Império..., ob. cit., capítulos IX, X, XIII e XIV; GONÇALVES, Andréa Lisly. Estratificação social e mobilizações políticas no processo de formação do Estado nacional Brasileiro: Minas Gerais, 1831-1835. São Paulo: Aderaldo \& Rothschild / Belo Horizonte: Fapemig, 2008; SILVA, Wlamir. Liberais e povo..., ob. cit., capítulo 7; ANDRADE, Marcos Ferreira de. Rebeldia e resistência: as revoltas escravas na província de Minas Gerais (1831-1840). Dissertação de Mestrado. Belo Horizonte: FAFICH - UFMG, 1996; REIS, João José. Rebelião escrava no Brasil: a história do Levante dos Malês (1835). São Paulo: Brasiliense, 1986; IDEM. A morte é uma festa: ritos fúnebres e revolta popular no Brasil do século XIX. São Paulo: Companhia das Letras, 1991. Vários artigos sobre as revoltas encontram-se em GRINBERG, Keila, e SALLES, Ricardo (org.). O Brasil imperial, v. II. Rio de Janeiro: Civilização Brasileira, 2009; e em DANTAS, Monica Duarte (org.). Revoltas, motins, revoluções: homens livres pobres e libertos no Brasil do século XIX. São Paulo: Alameda, 2011.

${ }^{18}$ Eram elas: Bahia, Pernambuco, Maranhão, Pará, Minas Gerais, Ceará, Paraíba, São Paulo, Rio Grande do Sul, Goiás, Santa Catarina, Alagoas, Rio Grande do Norte, Sergipe e Piauí. No Espírito Santo, uma tipografia chegou a ser instalada em 1840, mas o primeiro jornal só veio à luz dez anos depois.

${ }^{19}$ Cito apenas livros de referência já publicados que têm a imprensa como objeto: CONTIER, Arnaldo Daraya. Imprensa e ideologia em São Paulo (1822-1842): matizes do vocabulário político e social. Petrópolis: Vozes / Campinas: Unicamp, 1979; MOREL, Marco. As transformações..., ob. cit.; IDEM. Cipriano..., ob. cit.; RICCI, Maria Lúcia de Souza Rangel. A atuação política de um publicista: Antonio Borges da Fonseca. Número especial da revista Notícia bibliográfica e histórica, no 157. Campinas: Pontifícia Universidade Católica de Campinas, janeiro-junho de 1995; BASILE, Marcello Otávio. Ezequiel ..., ob. cit.; LIMA, Ivana Stolze, Cores, marcas e falas: sentidos da mestiçagem no Império do Brasil. Rio de Janeiro: Arquivo Nacional, 2003; SILVA, Wlamir. Liberais..., ob. cit.; FONSECA, Silvia Carla Pereira de Brito. A ideia de República..., ob, cit.; ARAÚJO, Dilton Oliveira de. O tutu da Bahia: transição conservadora e formação da nação, 1838-1850. Salvador: EDUFBA, 2009; OLIVEIRA, Carlos Eduardo França de. Poder local e palavra impressa: São Paulo, 18241834. São Paulo: Annablume / Fapesp, 2011; e IDEM. Construtores do Império, defensores da província: São Paulo e Minas Gerais na formação do estado nacional e dos poderes locais, 1823-1834. Porto Alegre: Puc-RS, 2017. Soma-se a isso, um número crescente de dissertações de mestrado e de teses de doutorado não publicadas, de capítulos de livros coletivos e de artigos em revistas acadêmicas.

${ }^{20}$ No caso do Rio de Janeiro, quase $58 \%$ dos periódicos em circulação durante as regências concentram-se nos anos de 1831 a 1833 (133, em um universo de 231), com destaque para este último ano, que, sozinho, representa quase um quarto do total (54). O restante distribui-se pelos sete anos seguintes, em tendência de queda progressiva, de modo que apenas $16 \%$ dos jornais (36) foram produzidos entre 1838 e 1840. Para efeito de comparação, no Rio de Janeiro foram publicados cerca de 77 jornais ao longo do Primeiro Reinado e de 155 na década inicial do Segundo Reinado. Cf. Basile, Marcello. Inventário analítico da imprensa periódica do Rio de Janeiro na Regência: perfil dos jornais e dados estatísticos. In: CARVALHO, José Murilo de, e NEVES, Lucia Maria Bastos P. (org.). Dimensões e fronteiras do Estado brasileiro no oitocentos. Rio de Janeiro: Eduerj, 2014. Pesquisa desenvolvida conjuntamente 
o acirramento dos conflitos no interior das elites política e intelectual, o desenvolvimento da esfera pública política, os debates acerca das reformas constitucionais e a proliferação de tipografias. Em contrapartida, o período das regências unas (1835-1840) foi marcado por progressivo recuo da imprensa, em especial na Corte, acompanhando o processo de desarticulação dos antigos grupos políticos, o rearranjo operado pelo Regresso conservador - com a consequente redução das margens de conflito intraelite -, o cerceamento à imprensa e a gradual retração da esfera pública. A grande maioria dos periódicos era composta por pasquins, jornais de caráter político, representantes de alguma facção, com pequeno formato, duração efêmera, periodicidade irregular e linguagem virulenta. Mas havia também folhas de linha comercial (com conteúdo informativo mais diversificado) e cultural (de cunho literário, científico ou religioso), e também aquelas dedicadas ao público feminino e aos chamados homens de cor.

Os trabalhos reunidos oportunamente neste dossiê representam bem as novas tendências historiográficas e apresentam um consistente e variado panorama da imprensa regencial, em diferentes regiões do Império ${ }^{21}$. Wlamir Silva analisa os jornais publicados em Minas Gerais, com ênfase nas disputas entre as facções políticas pela hegemonia na província; nos debates acerca das reformas constitucionais; e na reconfiguração das forças políticas provinciais a partir do surgimento do Regresso. As controvérsias em torno das reformas e, em particular, da questão federalista são abordadas também por Carlos Eduardo Oliveira, em seu estudo sobre os periódicos de São Paulo, que questiona a pretensa homogeneidade política paulista e ressalta as fissuras dentro do ideário liberal. Já Christiane Pereira descortina aspectos da cultura impressa do Rio Grande do Sul, nos anos precedentes à Revolução Farroupilha, confrontando dois jornais de tendências políticas rivais, cujo ponto central de desavenças era tanto o tema das reformas, quanto o da forma de governo. A centralidade dos embates referentes à tópica federalista é igualmente realçada por Silvia Fonseca, ao analisar os periódicos da Bahia e de Pernambuco, e suas conexões com associações políticas e com revoltas, assinalando o papel da imprensa enquanto guardiã das memórias locais. Relações da imprensa com outro tipo de movimento de rua - as festas cívicas -, na Bahia e na Corte na época do Regresso, são examinadas por Hendrik Kraay, que enfatiza as lutas políticas em torno desses rituais e da cobertura feita pelos jornais, bem como as releituras populares sobre eles. Por sua vez, Jorge Vianna e Arthur Reis elucidam aspectos da linguagem política veiculada pela imprensa no início da Regência, enfocando a defesa do federalismo e de uma identidade americana por um jornal da Corte, e sua peculiar inserção entre os moderados. Por fim, Adriana Campos, Marcello Basile e Fernanda Pandolfi analisam as vicissitudes da trajetória política multifacetada de Marcelino Pinto Ribeiro Duarte, capixaba que deixou o Espírito Santo para se instalar no Rio de Janeiro em busca de promoção política, notabilizando-se como padre, professor, publicista, insurreto e deputado geral.

Tais trabalhos apresentam, em suma, olhares ricos e complexos sobre as regências, enquanto momento crucial e singular dos processos de construção do Estado imperial e da nação brasileira. E atestam a relevância da imprensa - enquanto arena de participação política e intercâmbios culturais, inserida no âmbito do espaço público - não apenas como fonte ou como objeto de pesquisa; mas também como próprio agente histórico, capaz de influir sobre os acontecimentos de sua época e de produzir visões e memórias que, afinal, impõem ao historiador a grata tarefa de interpretá-las.

\section{Referências Bibliográficas}

AMARAL, Braz do. A Sabinada. In: PAEBa, v. II. Salvador, 1938.

AMARAL, José Ribeiro do. Apontamentos para a historia da revolução da Balaiada na provincia do Maranhão. 3 vs. Maranhão: Typ. Teixeira, 1898 / 1900 / 1906.

ANAIS do Segundo Congresso de História Nacional. 5 vs. In: RIHGB. Rio de Janeiro: Imprensa Nacional, 1941-1946.

ANDRADE, Manuel Correia de. Movimentos nativistas em Pernambuco: Setembrizada e Novembrada. Recife: Universidade Federal de Pernambuco, 1974.

ANDRADE, Marcos Ferreira de. Rebeldia e resistência: as revoltas escravas na província de Minas Gerais (1831-1840). Dissertação de Mestrado. Belo Horizonte: FAFICH - UFMG, 1996.

com Marco Morel.

${ }^{21}$ Outros artigos sobre a imprensa regencial já foram antes publicados na revista Almanack, como os de Silvia Fonseca, sobre o sistema conceitual do padre Lopes Gama (no 3, 2012/1); Marcos de Andrade e Janaina de Carvalho, acerca das representações de Evaristo da Veiga feita por jornais da Corte ( $\left.n^{\circ} 4,2012 / 2\right)$; e Ana Rosa Silva e Thaís Carvalho, sobre a crítica panfletária dos padres Perereca e Tilbury à vinda de missionários metodistas ( $\left.n^{\circ} 15,2017 / 1\right)$. 
ANDRADE, Marcos Ferreira de. Elites regionais e a formação do Estado imperial brasileiro: Minas Gerais Campanha da Princesa (1799-1850). Rio de Janeiro: Arquivo Nacional, 2008.

ANDRADE, Marcos Ferreira de, e SILVA, Janaína de Carvalho. Moderados, exaltados e caramurus no prelo carioca: os embates e as representações de Evaristo Ferreira da Veiga (1831-1835). In: Almanack, nº 4. Julho-dezembro de 2012,

ARAÚJO, Dilton Oliveira de. O tutu da Bahia: transição conservadora e formação da nação, 1838-1850. Salvador: EDUFBA, 2009.

ARAÚJO, Reginaldo Alves de. A parte no partido: relações de poder e política na formação do Estado nacional brasileiro, na província do Ceará (1821-1841). Tese de Doutorado. Fortaleza: PPGH - UFC, 2018.

AZEVEDO, Moreira de. Origem e desenvolvimento da imprensa no Rio de Janeiro. In: RIHGB, t. XXVIII parte segunda. Rio de Janeiro: B. L. Garnier, 1865.

AZEVEDO, Manuel Duarte Moreira de. Sedição militar na Ilha das Cobras em 1831. In: RIHGB, t. XXXIV parte 2. Rio de Janeiro: Typ. Imparcial, 1871.

AZEVEDO, Manuel Duarte Moreira de. Os tiros no theatro: motim popular no Rio de Janeiro. In: RIHGB, t. XXXVI - parte 2. Rio de Janeiro: Typ. Imparcial, 1873.

AZEVEDO, Manuel Duarte Moreira de. Sedição militar de julho de 1831 no Rio de Janeiro. In: RIHGB, t. XXXVII - parte 2. Rio de Janeiro: Typ. Imparcial, 1874.

AZEVEDO, Manuel Duarte Moreira de. Motim politico de 3 de abril de 1832 no Rio de Janeiro. In: RIHGB, t. XXXVII - parte 2. Rio de Janeiro: Typ. Imparcial, 1874.

AZEVEDO, Manuel Duarte Moreira de. Motim politico de 17 de abril de 1832 no Rio de Janeiro. In: RIHGB, t. XXXVIII - parte 2. Rio de Janeiro: Typ. Imparcial, 1875.

AZEVEDO, Manuel Duarte Moreira de. Motim politico de dezembro de 1833 no Rio de Janeiro: remoção do tutor do imperador. In: RIHGB, t. XXXIX - parte 2. Rio de Janeiro: Typ. Imparcial, 1876.

AZEVEDO, Manuel Duarte Moreira de. Sociedades fundadas no Brazil desde os tempos coloniaes até o começo do actual Reinado. In: RIHGB, t. XLVIII - parte 2. Rio de Janeiro: Typographia de Laemmert, 1885.

AZEVEDO, Moreira de. Historia patria: o Brazil de 1831 a 1840. Rio de Janeiro: B. L. Garnier, 1884.

BASILE, Marcello. Anarquistas, rusguentos e demagogos: os liberais exaltados e a formação da esfera pública na Corte imperial (1829-1834). Dissertação de Mestrado. Rio de Janeiro: PPGHIS - UFRJ, 2000.

BASILE, Marcello. Otávio. Ezequiel Corrêa dos Santos: um jacobino na Corte imperial. Rio de Janeiro: Editora FGV, 2001.

BASILE, Marcello. O Império em construção: projetos de Brasil e ação política na Corte regencial. Tese de Doutorado. Rio de Janeiro: PPGHIS - UFRJ, 2004.

BASILE, Marcello. Festas cívicas na Corte regencial. In: Varia Historia, v. 22 - nº 36. Belo Horizonte: Programa de Pós-Graduação em História da UFMG, julho-dezembro de 2006.

BASILE, Marcello. O laboratório da nação: a era regencial (1831-1840). In: GRINBERG, Keila, e SALLES, Ricardo (org.). O Brasil imperial, v. II: 1831-1870. Rio de Janeiro: Civilização Brasileira, 2009.

BASILE, Marcello. Inventário analítico da imprensa periódica do Rio de Janeiro na Regência: perfil dos jornais e dados estatísticos. In: CARVALHO, José Murilo de, e NEVES, Lucia Maria Bastos P. (org.). Dimensões e fronteiras do Estado brasileiro no oitocentos. Rio de Janeiro: Eduerj, 2014.

BASILE, Marcello. The "print arena": press, politics, and the public sphere in the Brazilian Empire, 1820s-1840s. In: CASTILHO, Celso, CRIBELLI, Teresa, e KRAAY, Hendrik (org.). Press, power, and culture in Imperial Brazil, 1822-1889. Albuquerque: University of New Mexico Press (no prelo).

BASTOS, Aureliano Cândido Tavares. A província: estudo sobre a descentralização no Brasil. $3^{\text {a }}$ ed. São Paulo: Nacional / Brasília: Instituto Nacional do Livro, 1975 (1ª ed. - 1870).

BRASIL, Joaquim Francisco de Assis. História da república rio-grandense. Porto Alegre: Cia. União de Seguros Gerais, 1982 [ $1^{\text {a }}$ ed. - 1882].

BRASIL, Joaquim Francisco de Assis. A Guerra dos Farrapos. Rio de Janeiro: Adersen, 1934.

CARVALHO, Alfredo de. A imprensa baiana de 1811-1898. In: Revista do Instituto Geographico e Historico da Bahia, v. 6 - nos 21-22. Bahia, 1899.

CARVALHO, Alfredo de. Jornaes pernambucanos de 1821-1898. Recife: Typographia do Jornal do Recife, 1899.

CARVALHO, Alfredo de. Annaes da imprensa periodica pernambucana de 1821 a 1908. Recife: Typographia do Jornal do Recife, 1908. 
CARVALHO, Alfredo de. Genese e progressos da imprensa periodica no Brazil. In: RIHGB, tomo consagrado à Exposição Commemorativa do Primeiro Centenario da Imprensa Periodica no Brazil - parte 1. Rio de Janeiro: Imprensa Nacional, 1908.

CARVALHO, Marcus Joaquim Maciel de. Hegemony and rebellion in Pernambuco (Brazil), 1821-1835. Tese de Doutorado. Urbana: University of Illinois at Urbana-Champaign, 1989.

CASTRO, Paulo Pereira de. A 'experiência republicana', 1831-1840. In: HOLANDA, Sérgio Buarque de (dir.), e CAMPOS, Pedro Moacyr (assist.). História geral da civilização brasileira, t. II - o Brasil monárquico, $2^{\circ}$ v. - dispersão e unidade. $5^{a}$ ed. São Paulo: Difel, 1985.

CHAMON, Carla Simone. Festejos imperiais: festas cívicas em Minas Gerais (1815-1845). Bragança Paulista: Edusf, 2002.

CONTIER, Arnaldo Daraya. Imprensa e ideologia em São Paulo (1822-1842): matizes do vocabulário político e social. Petrópolis: Vozes / Campinas: Unicamp, 1979.

DANTAS, Monica Duarte (org.). Revoltas, motins, revoluções: homens livres pobres e libertos no Brasil do século XIX. São Paulo: Alameda, 2011.

DI PAOLO, Pasquale. Cabanagem: a revolução popular da Amazônia. Belém: Conselho Estadual de Cultura, 1985.

DIAS, Claudete Maria Miranda. Balaios e bem-te-vis: a guerrilha sertaneja. Teresina: Fundação Cultural Monsenhor Chaves, 1995.

DOLHNIKOFF, Miriam. O pacto imperial: origens do federalismo no Brasil do século XIX. São Paulo: Globo, 2005.

FAZOLI FILHO, Arnaldo. O período regencial. 2a ed. São Paulo: Ática, 1994.

FONSECA, Gondin da. Biografia do jornalismo carioca (1808-1908). Rio de Janeiro: Quaresma, 1941.

FONSECA, Silvia Carla Pereira de Brito. A República em negativo: o sistema conceitual do padre Carapuceiro. In: Almanack, nº 3. Janeiro-junho de 2012.

FONSECA, Silvia Carla Pereira de Brito. A ideia de República no Império do Brasil: Rio de Janeiro e Pernambuco (1824-1834). Jundiaí: Paco, 2016.

FREITAS, Décio. Os guerrilheiros do imperador. Rio de Janeiro: Graal, 1978.

GONÇALVES, Andréa Lisly. Estratificação social e mobilizações políticas no processo de formação do Estado nacional Brasileiro: Minas Gerais, 1831-1835. São Paulo: Aderaldo \& Rothschild / Belo Horizonte: Fapemig, 2008.

GOUVÊA, Maria de Fátima Silva. O Império das províncias: Rio de Janeiro, 1822-1889. Rio de Janeiro: Civilização Brasileira, 2008.

GRINBERG, Keila, e SALLES, Ricardo (org.). O Brasil imperial, v. II. Rio de Janeiro: Civilização Brasileira, 2009.

GUIMARÃES, Lucia Maria Paschoal. Em nome da ordem e da moderação: a trajetória da Sociedade Defensora da Liberdade e da Independência Nacional do Rio de Janeiro. Dissertação de Mestrado. Rio de Janeiro: PPGHIS - UFRJ, 1990.

GUIMARÃES, Lucia Maria Paschoal. Da Escola Palatina ao Silogeu: Instituto Histórico e Geográfico Brasileiro (1889-1938). Rio de Janeiro: Museu da República, 2007.

HURLEY, Henrique Jorge. A Cabanagem. Belém: Livraria Clássica, 1936.

IPANEMA, Marcello, e IPANEMA, Cybelle. Imprensa na Regência: observações estatísticas e de opinião pública. In: RIHGB, v. 307. Rio de Janeiro: Departamento de Imprensa Nacional, 1976.

IPANEMA, Marcello, e IPANEMA, Cybelle. Imprensa fluminense: ensaios e trajetos. Rio de Janeiro: Instituto de Comunicação Ipanema, 1984.

JANOTI, Maria de Lourdes Mônaco. A Balaiada. São Paulo: Brasiliense, 1987.

KRAAY, Hendrik. Between Brazil and Bahia: celebrating Dois de Julho in nineteenth-century Salvador. In: Journal of Latin American Studies, no 31. Cambridge: Cambridge University Press, 1999.

KRAAY, Hendrik. Definindo nação e Estado: rituais cívicos na Bahia pós-Independência (1823-1850). In: Topoi: Revista de História, $\mathrm{n}^{\circ}$ 3. Rio de Janeiro: 7 Letras, setembro de 2001.

KRAAY, Hendrik. Days of national festivity in Rio de Janeiro, Brazil, 1823-1889. Stanford: Stanford University Press, 2013.

LEITMAN, Spencer. Raízes sócio-econômicas da Guerra dos Farrapos: um capítulo da história do Brasil no 
século XIX. Rio de Janeiro: Graal, 1979.

LENHARO, Alcir. As tropas da moderação: o abastecimento da Corte na formação política do Brasil, 18081842. São Paulo: Símbolo, 1979.

LIMA, Ivana Stolze. Cores, marcas e falas: sentidos da mestiçagem no Império do Brasil. Rio de Janeiro: Arquivo Nacional, 2003.

LINDOSO, Dirceu. A utopia armada: rebeliões de pobres nas matas do Tombo Real (1832-1850). Rio de Janeiro: Paz e Terra, 1983.

LYRA, Maria de Lourdes Viana. O Império em construção: Primeiro Reinado e Regências. São Paulo: Atual, 2000.

MOREL, Marco. Cipriano Barata na Sentinela da Liberdade. Salvador: Academia de Letras da Bahia / Assembléia Legislativa do Estado da Bahia, 2001.

MOREL, Marco. O período das Regências (1831-1840). Rio de Janeiro: Jorge Zahar, 2003.

MOREL, Marco. As transformações dos espaços públicos: imprensa, atores políticos e sociabilidades na Cidade Imperial (1820-1840). São Paulo: Hucitec, 2005.

NABUCO, Joaquim. Um estadista do Império. 2 vs. 5a ed. Rio de Janeiro: Topbooks, 1997 (1 $1^{\text {a }}$ ed., em 3 vs., 1897-1899).

LEAL, Aurelino. Do Acto Addicional à Maioridade (Historia constitucional e política). Rio de Janeiro: [Imprensa Naval], 1915.

LOPES, Juliana Serzedello Crespim. Identidades politicas e raciais na Sabinada (Bahia, 1837-1838). São Paulo: Alameda, 2013.

MAGALHÃES, Domingos José Gonçalves de. Memoria historica e documentada da revolução da provincia do Maranhão desde 1839 até 1840. In: RIHGB, t. X. $2^{\text {a }}$ ed. Rio de Janeiro: Typ. de João Ignacio da Silva, 1870 ( $1^{\text {a }}$ ed. - 1848).

NASCIMENTO, Luiz do. História da imprensa de Pernambuco (1821-1954). 14 vs. Recife: Universidade Federal de Pernambuco - Imprensa Universitária, 1967-1982.

NEEDELL, Jeffrey D. Party formation and State-making: the Conservative Party and the reconstruction of the brazilian State, 1831-1840. In: Hispanic American Historical Review, v. 81 - nº 2. Duke University Press, maio de 2001.

NEEDELL, Jeffrey D. The Party of Order: the conservatives, the State, and slavery in the Brazilian Monarchy, 1831-1871. Stanford: Stanford University Press, 2006.

OLIVEIRA, Carlos Eduardo França de. Poder local e palavra impressa: São Paulo, 1824-1834. São Paulo: Annablume / Fapesp, 2011.

OLIVEIRA, Carlos Eduardo França de. Construtores do Império, defensores da província: São Paulo e Minas Gerais na formação do estado nacional e dos poderes locais, 1823-1834. Porto Alegre: Puc-RS, 2017.

OTTONI, Cristiano Benedito. Autobiografia. Brasília: Editora da Universidade de Brasília, 1983 (1ª ed. - 1870).

OTTONI, Theophilo Benedicto. Circular Dedicada aos Srs. Eleitores de Senadores pela Provincia de MinasGeraes. In: Revista do Instituto Historico e Geographico Brasileiro - RIHGB, Rio de Janeiro, t. LXXVIII - parte II, p. 205-256, . $2^{\text {a }}$ ed., 1916 (1 $1^{\text {a }}$ ed. - 1860).

PEREIRA, Christiane Peres. O pacto constitucional: a dinâmica política entre Corte e províncias no Império do Brasil (1823-1834). Tese de Doutorado. Seropédica: PPHR - UFRRJ, 2018.

PESAVENTO, Sandra Jatahy et alii. A Revolução Farroupilha: história e interpretação. Porto Alegre: Mercado Aberto, 1985.

PINHEIRO, Luís Balkar Sá Peixoto. Visões da Cabanagem: uma revolta popular e suas representações na historiografia. Manaus: Valer, 2001.

POPPINO, Rollie E. A Regência e a história do Brasil: um desafio aos historiadores. In: RIHGB, Rio de Janeiro, v. 307, 1976.

RAIOL, Domingos Antônio. Motins políticos, ou história dos principais acontecimentos políticos da província do Pará desde o ano de 1821 até 1835. 3 vs. $2^{\text {a }}$ ed. [Belém]: Universidade Federal do Pará, 1970 [1ª ed. - 1865].

RANGEL, Genaro. Semeadura e colheita: memória histórica da Imperial Sociedade Amante da Instrução. Belo Horizonte: O Lutador, 1979.

REIS, João José. Rebelião escrava no Brasil: a história do Levante dos Malês (1835). São Paulo: Brasiliense, 1986. 
REIS, João José. A morte é uma festa: ritos fúnebres e revolta popular no Brasil do século XIX. São Paulo: Companhia das Letras, 1991.

RIBEIRO, Gladys Sabina. A liberdade em construção: identidade nacional e conflitos antilusitanos no Primeiro Reinado. Rio de Janeiro: Relume Dumará / Faperj, 2002.

RIBEIRO, José Iran. O Império e as revoltas: estado e nação nas trajetórias dos militares do Exército imperial no contexto da Guerra dos Farrapos. Rio de Janeiro: Arquivo Nacional, 2013.

RICCI, Maria Lúcia de Souza Rangel. A atuação política de um publicista: Antonio Borges da Fonseca. Número especial da Revista Notícia Bibliográfica e Histórica, nº 157. Campinas: Pontifícia Universidade Católica de Campinas, janeiro-junho de 1995.

ROCHA, Justiniano José da. Acção; reacção; transacção. Duas palavras acerca da actualidade politica do Brazil. Rio de Janeiro, Typ. Imp. e Const. de J. Villeneuve e Comp., 1855.

SALLES, Vicente. Memorial da cabanagem: esboço do pensamento político-revolucionário no Grão-Pará. Belém: Cejup, 1992.

SANTOS, Maria Januária Vilela. A Balaiada e a insurreição de escravos no Maranhão. São Paulo: Ática, 1983.

SERRA, Astolfo. A Balaiada. Rio de Janeiro: Biblioteca do Exército, 1946.

SILVA, Ana Rosa Cloclet da, e CARVALHO, Thaís da Rocha. Ultramontanismo e protestantismo no período regencial: uma análise da crítica panfletária dos padres Perereca e Tilbury à missão metodista no Brasil. In: Almanack, nº 15. Janeiro-junho de 2017.

SILVA, João Manuel Pereira da. Memórias do meu tempo. 2a ed. Brasília: Senado Federal, 2003.

SILVA, José Luiz Werneck da. A Sociedade Auxiliadora da Indústria Nacional (1827-1904) na formação social brasileira: a conjuntura de 1871 a 1877. Dissertação de Mestrado. 2 vs. Niterói: ICHF - Uff, 1979.

SILVA, Wlamir. Liberais e povo: a construção da hegemonia liberal-moderada na província de Minas Gerais (1830-1834). São Paulo: Hucitec / Belo Horizonte: Fapemig, 2009.

SLEMIAN, Andréa. Sob o império das leis: constituição e unidade nacional na formação do Brasil (1822-1834). São Paulo: Aderaldo \& Rothschild / Fapesp, 2009.

SODRÉ, Nelson Werneck. A história da imprensa no Brasil. Rio de Janeiro: Civilização Brasileira, 1966.

SOUZA, Octavio Tarquinio de. História dos fundadores do Império do Brasil. 10 vs. Rio de Janeiro: José Olympio, 1957.

SOUZA, Paulo César. A Sabinada: a revolta separatista da Bahia, 1837. São Paulo: Círculo do Livro, 1987.

TIMANDRO (Francisco de Salles Torres Homem). O libelo do povo. In: MAGALHÃES JÚNIOR, Raimundo (org.). Três panfletários do Segundo Reinado. São Paulo: Nacional, 1956, pp. 75-92 (1ª ed. - 1849).

URUGUAI, Visconde do. Ensaio sobre o direito administrativo. In: IDEM. Visconde do Uruguai. Organização, introdução e notas de José Murilo de Carvalho. São Paulo: Editora 34, 2002 (1ª ed. - 1862).

VALLADÃO, Alfredo. Da Aclamação à Maioridade (1822-1840) e outros trabalhos históricos. $3^{\text {a }}$ ed. Rio de Janeiro: Freitas Bastos, 1973 [1ª ed. - 1937].

VARELA, Alfredo. Revoluções cisplatinas: a república rio-grandense. 2 vs. Porto: Chardron, 1915.

VIANNA, Helio. Contribuição à história da imprensa brasileira (1812-1869). Rio de Janeiro: Imprensa Nacional / Ministério da Educação e Saúde - Instituto Nacional do Livro, 1945.

VIANNA FILHO, Luiz. A Sabinada (a República bahiana de 1837). Rio de Janeiro: José Olympio, 1938.

WERNET, Augustin. As sociedades políticas da província de São Paulo na primeira metade do período regencial. Tese de Doutorado. 2 vs. São Paulo: FFLCH - Usp, 1975.

WERNET, Augustin. Sociedades políticas (1831-1832). São Paulo: Cultrix / Brasília: Instituto Nacional do Livro, 1978.

Recebido em: 05/11/2018 - Aprovado em: 20/11/2018

$* * *$

O presente trabalho (todo o número 20 da Revista Almanack) foi realizado com apoio da Coordenação de Aperfeiçoamento de Pessoal de Nível Superior - Brasil (CAPES) - Código de Financiamento 001 